34. Cnattingius S, Bergstrom R, Lipworth L, et al. Prepregnancy weight and the risk of adverse pregnancy outcomes. N Engl J Med 1998;338:147-52.

35. Cedergen MI. Maternal morbid obesity and the risk of adverse pregnancy outcome. Obstet Gynecol 2004;103:219-24.

36. Nohr EA, Bech BH, Davies MJ, et al. Prepregnancy obesity and fetal death: a study within the Danish national birth cohort. Obstet Gynecol 2005;106:250-9.

37. Dixit A, Girling JC. Obesity and pregnancy. J Obstet Gynaecol 2008;28:14-23.

38. Bertrand JM, Riley SP, Popkin J, et al. The long term pulmonary sequelae of prematurity: the role of familial airway hyperreactivity and the respiratory distress syndrome. $N$ Engl J Med 1985;312:742-5.

39. Riedel F, Achenbach U, Rieger CHL. Prematurity and maternal bronchial hyperresponsiveness, J Perinat Med 1989:17:151-5.

40. Milne F, Redman C, Walker J, et al. The preeclampsia community guidelines (PRECOG): how to screen for and detect onset of pre-eclampsia in the community. BMJ 2005;330:576-80.

41. Millar EA, Nally JE, Thomson NC. Angiotensin II potentiates methacholine-induced bronchoconstriction in human airway both in vitro and in vivo. Eur Respir $J$ 1995;8:1838-41.

42. Levin ER. Endothelins. N Eng/ J Med 1995;10:356-63.

43. Siddiqui S, Goodman N, McKenna S, et al. Preeclampsia is associated with airway

hyperresponsiveness. Br J Obstet Gynaecol 2008;115:520-2.

44. Schatz M, Zeiger RS, Harden K, et al. The safety of asthma and allergy medications during pregnancy. J Allergy Clin Immunol 1997;100:301-6.

45. Norjavaara E, de Verdier MG. Normal pregnancy outcomes in a population-based study including 2968 pregnant women exposed to budesonide. J Allergy Clin Immunol 2003;111:736-42.

46. Schatz M, Dombrowski MP, Wise, et al. The relationship of asthma medication use to perinatal outcome. J Allergy Clin Immunol 2004;113:1040-5.

47. Martel MJ, Rey E, Beauchesne MF, et al. Use of inhaled corticosteroids during pregnancy and risk of pregnancy-induced hypertension: nested case-control study. BMJ 2005;330:230-6.

48. Bakhireva LN, Jones KL, Schatz M, et al. Asthma medication use in pregnancy and fetal growth. Allergy Clin Immunol 2005;116:503-9.

49. Martel MJ, Rey E, Beauchesne MF, et al. Use of short-acting $\beta_{2}$-agonists during pregnancy and the risk of pregnancy-induced hypertension. J Allergy Clin Immunol 2007:119:576-82.

50. Bracken MB, Trichew EW, Belanger K, et al. Asthma symptoms, severity, and drug therapy: a prospective study of effects on 2205 pregnancies. Obstet Gynecol 2003;102:739-52.

51. Bakhirebva LN, Schatz M, Jones KL, et al. Asthma control during pregnancy and the risk of preterm delivery or impaired fetal growth. Ann Allergy Asthma Immunol 2008;101:137-43.

52. Schatz M, Zeiger RS, Hoffman CP, et al. Intrauterine growth is related to gestational pulmonary function in pregnant asthmatic women. Chest 1990;98:389-92.

53. Schatz M, Dombrowski MP, Wise R, et al Spirometry is related to perinatal outcomes in pregnant women with asthma. Am J Obstet Gynecol 2006;194:120-6.

54. Murphy VE, Clifton VL, Gibson PG. Asthma exacerbations during pregnancy: incidence and association with adverse pregnancy outcomes. Thorax 2006;61:169-76.

55. NAEPP Expert Panel Report. Managing asthma during pregnancy: recommendations for pharmacologic treatment-2004 update. J Allergy Clin Immunol 2005:115:34-46.

\title{
The pulmonary protein C system: preventive or therapeutic target in acute lung injury?
}

\section{Marcus J Schultz, ${ }^{1,2,3}$ Barry Dixon, ${ }^{4}$ Marcel Levi ${ }^{5}$}

Acute lung injury or its more severe form-acute respiratory distress syndrome (ARDS) - are common and important intensive care syndromes affecting many patients. Acute lung injury is characterised by damage to the alveolarcapillary membrane resulting in alveolar flooding, pulmonary inflammation and alveolar coagulopathy, and changes in surfactant properties with severe impairment of oxygenation and respiratory failure mandating mechanical ventilation. It is rarely present at the time of hospital admission but develops over a period of hours to days in subsets of patients with predisposing conditions such as trauma,

\footnotetext{
${ }^{1}$ Department of Intensive Care Medicine, Academic Medical Center, University of Amsterdam, Amsterdam, The Netherlands; ${ }^{2}$ Laboratory of Experimental Intensive Care and Anesthesiology (LEICA), Academic Medical Center, University of Amsterdam, Amsterdam, The Netherlands; ${ }^{3}$ HERMES Critical Care Group, Amsterdam, The Netherlands; ${ }^{4}$ Department of Intensive Care Medicine, St Vincent's Hospital, Melbourne, Australia; ${ }^{5}$ Department of Internal Medicine, Academic Medical Center, University of Amsterdam, Amsterdam, The Netherlands
}

Correspondence to: Dr M J Schultz, Department of Intensive Care Medicine, Academic Medical Center, Meibergdreef 9, 1105 AZ Amsterdam, The Netherlands; m.j.schultz@amc.uva.nl shock or sepsis, and accompanying interventions including mechanical ventilation and transfusion. ${ }^{1}$ Acute lung injury may therefore be viewed as a potentially preventable complication. Indeed, implementation of acute lung injury prevention strategies such as lung-protective mechanical ventilation using normal-sized tidal volumes and restrictive blood transfusion leads to a significant decrease in acute lung injury and mortality of mechanically ventilated patients. ${ }^{2}$ Pharmacotherapies targeting progression to acute lung injury may also benefit patients at risk of this complication. One such preventive strategy might be attenuation of pulmonary coagulopathy.

\section{COAGULOPATHY IN ACUTE LUNG INJURY}

Recent studies have shown that prominent changes in alveolar fibrin turnover are intrinsic to acute lung injury. ${ }^{3}$ The profile and extent of these changes vary with the severity of the injury. ${ }^{4}$ The mechanisms that contribute to pulmonary coagulopathy in acute lung injury are supposed to be similar to those found in the intravascular spaces in severe systemic inflammation (eg, sepsis or septic shock). ${ }^{5-7}$ Indeed, in acute lung injury, alveolar thrombin generation seems to be mediated, at least in part, by the tissue factor (TF)-factor VIIa (FVIIa) pathway, as the alveolar epithelium has been found to initiate TF-dependent intraalveolar coagulation in response to inflammation. ${ }^{8}$ Patients with ARDS show an increase in soluble TF, FVIIa and TFdependent factor $\mathrm{X}$ activation in bronchoalveolar lavage (BAL) fluid. ${ }^{56}$ Similarly, patients who develop ventilator-associated pneumonia have a rise in soluble TF and FVII in BAL fluid over time.? Furthermore, in ARDS, inhibition of the TF-FVIIa pathway completely abrogates intrapulmonary fibrin deposition. ${ }^{9}$ In association with enhanced fibrin production, fibrinolytic activity is depressed in BAL fluid of patients with acute lung injury or ARDS, ${ }^{4}$ related to raised levels of plasminogen activator inhibitor 1 (PAI-1), the main inhibitor of fibrinolysis. PAI- 1 is increased in acute lung injury and is probably secreted by lung epithelial cells, fibroblasts and endothelial cells. ${ }^{10}{ }^{11}$ Patients at risk of ventilator-associated pneumonia show similar changes in pulmonary fibrin breakdown. ${ }^{7}$ Although the lung has only a limited capacity to produce protein $\mathrm{C}$, activated protein $\mathrm{C}$ (APC) is present in BAL fluid. ${ }^{12}$ The protein $\mathrm{C}$ system is suppressed in patients with ventilator-associated pneumonia ${ }^{13}$ and acute lung injury or ARDS. ${ }^{14}$

\section{ANTICOAGULANT TREATMENT IN CRITICAL CARE PRACTICE}

Recombinant human activated protein $\mathrm{C}$ for severe sepsis and septic shock

Intravascular fibrin formation with sepsis is thought to perpetuate diffuse 
endothelial damage in multiple organs, contributing to multiple organ dysfunction and eventually death. Three recent randomised controlled trials studied the effect of recombinant human (rh)-APC infusion in sepsis. One trial (PROWESS) reported a significant reduction in mortality with the use rh-APC in patients with sepsis. ${ }^{15}$ Two subsequent trials (ADDRESS and RESOLVE) were negative, showing no reduction in mortality. ${ }^{16}{ }^{17}$ These latter two trials, however, can neither be seen as confirmatory nor "negative" for several reasons. First, the study populations were different from the population in the initial trial. Indeed, because the ADDRESS trial ${ }^{16}$ enrolled patients at low risk of death and not patients with severe sepsis, the results of this trial cannot and should not be used to draw any conclusions regarding the evidence for benefit of infusion of rh-APC. Interestingly, though, when patients with a high risk of death in the ADDRESS trial are analysed separately, the differences in mortality between patients treated with rh-APC and placebo resemble the difference in mortality in the PROWESS trial. Similar problems exist with the interpretation of the RESOLVE trial ${ }^{17}$ which studied paediatric patients. Severe disease outcome in children may be completely different from that in adults. It is therefore not justifiable to use the negative findings in this trial as evidence against the benefit of rh-APC in adults. International guidelines therefore clearly support the use of $\mathrm{rh}-\mathrm{APC}$ in patients with severe sepsis or septic shock. ${ }^{18}$

\section{Recombinant human activated protein $\mathrm{C}$ for lung injury?}

While infusion of rh-APC has been found to reduce mortality in patients with severe sepsis, ${ }^{15}$ many patients included in this trial had concomitant acute lung injury or ARDS, and many had pneumonia as the primary source of sepsis. ${ }^{19}$ One can question whether the beneficial effect of rh-APC is solely the result of its effect on intravascular coagulopathy since it exerts an anticoagulant effect in the lung as well. Indeed, activation of coagulation after pulmonary challenge with endotoxin is attenuated by intravenous rhAPC. ${ }^{20}$ Concurrently, increased PAI-1 activity is diminished by rh-APC. Thus, systemic administration of rh-APC influences pulmonary fibrin turnover and therefore may benefit patients with acute lung injury or ARDS, even in the absence of severe sepsis or septic shock. To date, only one study has been published on the effect of rh-APC in patients with acute lung injury. ${ }^{21}$ In this study, eligible subjects were critically ill patients who met the consensus criteria for acute lung injury; those with severe sepsis and a high chance of dying were excluded. Although there was no difference between patients receiving placebo or rhAPC in the number of ventilator-free days or in 60-day mortality, rh-APC decreased pulmonary dead space fraction.

\section{ACTIVATED PROTEIN C FOR HYPEROXIA- INDUCED LUNG INJURY IN MICE: A PREVENTIVE OR THERAPEUTIC MEASURE?}

In this issue of Thorax, Looney et a ${ }^{22}$ report their findings on the ability of recombinant murine APC (mAPC) to attenuate hyperoxia-induced acute lung injury in mice (see page 114). Hyperoxia produces dramatic increases in lung vascular permeability and extravascular lung water, and adversely affects lung fluid balance. Despite procoagulant changes in the lung with hyperoxia, the investigators found that intratracheal administration of recombinant $\mathrm{mAPC}$ did not ameliorate a number of measures of hyperoxia-induced lung injury, although the impact on BAL fluid levels of thrombin-antithrombin complex or histological evidence of fibrin deposition in the alveolar space or microvasculature were not assessed. An increase in BAL fluid levels of PAI-1 was prevented with intratracheal recombinant mAPC treatment, indicating that recombinant mAPC does affect pulmonary coagulopathy in this model of acute lung injury. As the authors themselves point out, the importance of PAI-1 in the pathogenesis of hyperoxic lung injury is endorsed by the survival advantage of PAI-1 knockout mice. $^{23}$ When genetically deleted, PAI-1 may allow enhanced clearance of intraalveolar fibrin and subsequent improved gas exchange. Recombinant mAPC was found only to affect BAL fluid levels of PAI-1 when given as treatment (at one time point after $48 \mathrm{~h}$ of hyperoxia) and not when given as a preventive measure (every $24 \mathrm{~h}$ starting from day 0 up to 72 or $96 \mathrm{~h}$ ); the reasons for this are not entirely clear. It remains uncertain how to translate this finding to clinical practice in which supportive measures such as mechanical ventilation may prevent patients from dying because of respiratory failure due to increases in lung vascular permeability and extravascular lung water. Prevention of increased BAL fluid levels of PAI-1 may potentially be of more benefit under these circumstances.

\section{CAN OR SHOULD ANTICOAGULANT TREATMENT BE A LOCAL STRATEGY?}

The study by Looney et a ${ }^{22}$ confirms other animal studies specifically targeting pulmonary coagulopathy. ${ }^{24-26}$ Of note, coagulopathy in acute lung injury is merely restricted to the pulmonary compartment. Local treatment such as direct intratracheal instillation or nebulisation may allow higher local concentrations, thereby potentially increasing local efficacy while limiting the risk of systemic bleeding. Looney et al successfully tested the intratracheal route of delivery with recombinant $\mathrm{mAPC}{ }^{22}$ We recently tested nebulisation of several anticoagulants and found similar results, ${ }^{27}$ and other animal studies have confirmed the potential beneficial effects of nebulised anticoagulants. ${ }^{28-30}$ The results from these preclinical studies are in line with studies in humans showing that administration of heparin to the lower respiratory tract by nebulisation is feasible and safe. ${ }^{31-33}$ In paediatric patients suffering from inhalation injury, nebulised heparin even seems to reduce mortality. ${ }^{34}$

\section{CONCLUSION}

Alveolar coagulopathy is intrinsic to acute lung injury. Several studies show that anticoagulant therapies effectively attenuate disturbed alveolar fibrin turnover with this severe complication. It is obvious that local therapy has the advantage of limiting the risk of systemic bleeding with anticoagulation. Whether we should go for preventive or therapeutic strategies remains to be established in further experiments. More preclinical and clinical studies are needed to determine whether anticoagulant strategies benefit subjects with acute lung injury before such treatment is advocated as standard practice in these patients.

Competing interests: None.

Thorax 2009;64:95-97. doi:10.1136/thx.2008.106955

\section{REFERENCES}

1. Iscimen R, Cartin-Ceba R, Yilmaz M, et al. Risk factors for the development of acute lung injury in patients with septic shock: an observational cohort study. Crit Care Med 2008;36:1518-22.

2. Yilmaz M, Keegan MT, Iscimen R, et al. Toward the prevention of acute lung injury: protocol-guided limitation of large tidal volume ventilation and inappropriate transfusion. Crit Care Med 2007;35:1660-7.

3. Schultz MJ, Haitsma JJ, Zhang H, et al. Pulmonary coagulopathy as a new target in therapeutic studies of acute lung injury or pneumonia-a review. Crit Care Med 2006;34:871-7.

4. Gunther A, Mosavi P, Heinemann S, et al. Alveolar fibrin formation caused by enhanced procoagulant and depressed fibrinolytic capacities in severe pneumonia. Comparison with the acute respiratory distress syndrome. Am J Respir Crit Care Med 2000;161:454-62. 
5. Idell S, Gonzalez K, Bradford H, et al. Procoagulant activity in bronchoalveolar lavage in the adult respiratory distress syndrome. Contribution of tissue factor associated with factor VII. Am Rev Respir Dis 1987;136:1466-74

6. Idell S, Koenig KB, Fair DS, et al. Serial abnormalities of fibrin turnover in evolving adult respiratory distress syndrome. Am J Physiol 1991;261:L240-8.

7. Schultz MJ, Millo J, Levi M, et al. Local activation of coagulation and inhibition of fibrinolysis in the lung during ventilator associated pneumonia. Thorax 2004;59:130-5.

8. Bastarache JA, Wang $L$, Geiser $T$, et al. The alveolar epithelium can initiate the extrinsic coagulation cascade through expression of tissue factor. Thorax 2007;62:608-16.

9. Miller DL, Welty-Wolf K, Carraway MS, et al. Extrinsic coagulation blockade attenuates lung injury and proinflammatory cytokine release after intratracheal lipopolysaccharide. Am J Respir Cell Mol Biol 2002;26:650-8.

10. Marshall BC, Sageser DS, Rao NV, et al. Alveolar epithelial cell plasminogen activator. Characterization and regulation. J Biol Chem 1990;265:8198-204.

11. Idell S. Endothelium and disordered fibrin turnover in the injured lung: newly recognized pathways. Crit Care Med 2002;30:S274-80.

12. Yamamoto K, Loskutoff DJ. Extrahepatic expression and regulation of protein $\mathrm{C}$ in the mouse. Am J Pathol 1998;153:547-55.

13. Choi G, Schultz MJ, Levi M, et al. Protein C in pneumonia. Thorax 2005:60:705-6.

14. Hataji 0, Taguchi 0 , Gabazza EC, et al. Activation of protein C pathway in the airways. Lung 2002;180:47-59.

15. Bernard GR, Vincent JL, Laterre PF, et al. Efficacy and safety of recombinant human activated protein $\mathrm{C}$ for severe sepsis. N Engl J Med 2001:344:699-709.
16. Abraham E, Laterre PF, Garg R, et al. Drotrecogin alfa (activated) for adults with severe sepsis and a low risk of death. N Engl J Med 2005;353:1332-41.

17. Nadel S, Goldstein B, Williams MD, et al. Drotrecogin alfa (activated) in children with severe sepsis: a multicentre phase III randomised controlled trial. Lancet 2007;369:836-43.

18. Dellinger RP, Levy MM, Carlet JM, et al. Surviving Sepsis Campaign: international guidelines for management of severe sepsis and septic shock: 2008. Crit Care Med 2008;36:296-327

19. Laterre PF, Garber G, Levy H, et al. Severe community-acquired pneumonia as a cause of severe sepsis: data from the PROWESS study. Crit Care Med 2005:33:952-61.

20. van der Poll T, Levi M, Nick JA, et al. Activated protein $C$ inhibits local coagulation after intrapulmonary delivery of endotoxin in humans. Am J Respir Crit Care Med 2005;171:1125-8.

21. Liu KD, Levitt J, Zhuo H, et al. Randomized clinical trial of activated protein $\mathrm{C}$ for the treatment of acute lung injury. Am J Respir Crit Care Med 2008:178:618-23.

22. Looney MR, Esmon CT, Matthay MA. Role of coagulation pathways and treatment with activated protein $\mathrm{C}$ in hyperoxic lung injury in mice. Thorax 2009;64:114-20.

23. Barazzone C, Belin D, Piguet PF, et al. Plasminogen activator inhibitor-1 in acute hyperoxic mouse lung injury. J Clin Invest 1996;98:2666-73.

24. Choi G, Hofstra JJ, Roelofs JJ, et al. Recombinant human activated protein $\mathrm{C}$ inhibits local and systemic activation of coagulation without influencing inflammation during Pseudomonas aeruginosa pneumonia in rats. Crit Care Med 2007;35:1362-8.

25. Choi G, Vlaar AP, Schouten M, et al. Natural anticoagulants limit lipopolysaccharide-induced pulmonary coagulation but not inflammation. Eur Respir J 2007;30:423-8.

26. Choi G, Hofstra JJ, Roelofs JJ, et al. Antithrombin inhibits bronchoalveolar activation of coagulation and limits lung injury during Streptococcus pneumoniae pneumonia in rats. Crit Care Med 2008;36:204-10.

27. Hofstra JJ, Cornet AD, Vlaar AP, et al. Nebulized antithrombin attenuates bacterial outgrowth in experimental streptococcus pneumoniae pneumonia in rats (abstract). Intensive Care Med 2008;34:S263.

28. Murakami K, McGuire R, Cox RA, et al. Heparin nebulization attenuates acute lung injury in sepsis following smoke inhalation in sheep. Shock 2002;18:236-41.

29. Enkhbaatar P, Cox RA, Traber LD, et al. Aerosolized anticoagulants ameliorate acute lung injury in sheep after exposure to burn and smoke inhalation. Crit Care Med 2007 Oct 23 [Epub ahead of print].

30. Enkhbaatar P, Esechie A, Wang J, et al. Combined anticoagulants ameliorate acute lung injury in sheep after burn and smoke inhalation. Clin Sci (Lond) 2008;114:321-9.

31. Bendstrup KE, Chambers CB, Jensen Jl, et al. Lung deposition and clearance of inhaled (99m)Tc-heparin in healthy volunteers. Am J Respir Crit Care Med 1999;160:1653-8.

32. Bendstrup KE, Gram J, Jensen Jl. Effect of inhaled heparin on lung function and coagulation in healthy volunteers. Eur Respir J 2002;19:606-10.

33. Dixon B, Santamaria JD, Campbell DJ. A phase 1 trial of nebulised heparin in acute lung injury. Crit Care 2008;12:R64.

34. Desai MH, Mlcak R, Richardson J, et al. Reduction in mortality in pediatric patients with inhalation injury with aerosolized heparin/N-acetylcystine therapy. J Burn Care Rehabil 1998:19:210-2.

\section{Pleural ultrasound}

\section{David Feller-Kopman}

The use of hand-held portable ultrasound (US) has probably had more of an impact in the care of patients with pleural effusions than any other development since Light introduced a method for distinguishing transudative from exudative effusions in $1972 .{ }^{1}$ The advantages of US for the evaluation of pleural effusions include the ability to provide real-time guidance for procedures, the absence of radiation, portability and the ability to perform dynamic evaluations. US is more sensitive than chest radiography for the detection of pleural fluid and may be better than chest CT scanning for differentiating pleural effusion from pleural thickening. The use of US has also been associated with a reduction in "near misses" as well as an increased yield, even in experienced hands. ${ }^{2}$ Because of these benefits, the use of US by non-radiologists has increased tremendously over the last

Correspondence to: Dr D Feller-Kopman, Interventional Pulmonology, Johns Hopkins Hospital, 1830 East Monument St, Fifth Floor, Baltimore, MD 21205, USA; dfellerk@jhmi.edu few years. The American Board of Internal Medicine "strongly recommends" obtaining proficiency in the use of US to guide thoracentesis for fellows in pulmonary and critical care training programmes (http://www.abim.org/certification/policies/imss/ccm.aspx). Likewise, the American College of Emergency Physicians, ${ }^{3}$ the American College of Surgeons ${ }^{4}$ and the Royal College of Radiology ${ }^{5}$ have all issued statements regarding the incorporation of US in the care of patients with pleural effusions.

There have been several recent reviews of the use of US to guide thoracentesis ${ }^{67}$ and, when compared with historical controls, the use of US is associated with a significant reduction in complications as well as improved yield. ${ }^{2}{ }^{9}$ In addition, the sonographic characteristics of effusions have been shown to correlate with underlying pathology. Complex effusions (with or without septae) and homogenously echogenic effusions are usually exudative, whereas anechoic effusions could be either exudative or transudative. ${ }^{10} 11$ The sonographic characteristics of effusions have also been found to predict the need for pleural intervention in patients with empyema. ${ }^{12}$ To date, however, only the presence of a pleural mass and the "echogenic swirling pattern" have been suggestive of the presence of a malignant pleural effusion (MPE). ${ }^{13} 14$

In this issue of Thorax, Qureshi and colleagues ${ }^{15}$ by using a systematic approach to the patient with suspected MPE, were able to accurately identify patients with malignant and benign disease (see page 139). Thoracic US was performed without clinical history and considered consistent with MPE if diaphragmatic/parietal pleural nodules, pleural thickening $>1 \mathrm{~cm}$ or hepatic metastases were found. The inability to resolve the five distinct layers of the diaphragm which are normally easily seen and a diaphragm thickness $>7 \mathrm{~mm}$ were also associated with malignant effusions. Benign disease was considered present when infection was confirmed or patients had a clinical follow-up of at least 12 months. Thoracic US correctly diagnosed 26/33 patients with malignant disease and 19/19 patients with benign disease (sensitivity $79 \%$, specificity $100 \%$, positive predictive value $100 \%$ and negative predictive value $73 \%$ ) for differentiating malignant from benign disease. In comparison with chest CT scanning as 